\title{
CONFRONTANDO O CONCEITO DE COMPETÊNCIAS PELA SUA DIVERSIDADE E APLICAÇÃO: UM OLHAR ENTRE A TEORIA E A PRÁTICA
}

\section{CONFRONTING SKILLS CONCEPT FOR DIVERSITY AND ITS APPLICATION: A LOOK BETWEEN THEORY AND PRACTICE}

\author{
Wesley Antonio Gonçalves \\ Doutorando em Administração na Universidade Metodista de Piracicaba - UNIMEP e docente efetivo do Instituto Federal do Triângulo \\ Mineiro - IFTM \\ Uberlândia, MG, Brasil \\ E-mail: professorwesley@gmail.com \\ Wiliam Machado de Andrade \\ Doutorando em Administração na Universidade Metodista de Piracicaba - UNIMEP e docente na Universidade Federal de Santa \\ Catarina - UFSC \\ Florianópolis, SC, Brasil \\ E-mail: wilian@usp.br

\section{Dalila Alves Corrêa} \\ Professora do Núcleo Permanente do Programa de Pós-Graduação em Administração da Universidade Metodista de Piracicaba - \\ UNIMEP \\ Piracicaba, SP, Brasil \\ E-mail: dcorreia@msn.com

\section{Gabriela Garcia Ribeiro} \\ Pesquisadora do Centro de Estudos Avançados em Economia Aplicada da Universidade de São Paulo - USP/Esalq e Mestranda em \\ Administração pela Universidade Metodista de Piracicaba - UNIMEP \\ Piracicaba, SP, Brasil \\ E-mail: gabi@usp.br
}

\section{RESUMO}

Duas questões de pesquisa foram definidas como objetivo neste estudo: a primeira procurou saber se os sujeitos da pesquisa demonstram inclinações conceituais a alguma das definições deste termo apontadas na literatura e, a segunda investigou a demanda por competências no contexto de trabalho destes sujeitos visando apurar a sua variabilidade. Utilizou-se aplicação de entrevistas qualitativas, semiestruturadas junto a um grupo de nove profissionais de um centro de estudos e pesquisa aplicada de uma instituição pública de ensino superior. Adotou-se a análise de conteúdo para o processo de apuração das informações decorrentes das entrevistas. Os resultados apontaram uma inclinação conceitual correspondente à competência enquanto propriedade do indivíduo, o que estabelece relação com a corrente teórica francesa. Em relação a demanda por competências a maioria dos sujeitos afirmam que há variabilidade em função da natureza dos projetos que desenvolvem, sendo o mercado balizador da dinâmica das competências

Palavras-chave: Competência. Gestão por Competência. Gestão de Pessoas. Conhecimento, Habilidade e Atitude. Competências Essenciais.

\section{ABSTRACT}

Two research questions were defined in this study: the first examined whether the subjects demonstrate conceptual leanings to any of the definitions of the term mentioned in the literature and the second investigated the demand for skills in the workplace these subjects in order to establish the variability. We used application of qualitative interviews, semistructured with the group of nine professionals from a center of studies and applied research of a public institution of higher education. Adopted the content analysis to the process of verification of the information in the interviews. The results showed a corresponding conceptual slope jurisdiction as property of the individual, establishing relationship with the French theoretical current. Regarding the demand for skills most subjects say that there is variability in the nature of the projects we develop, and the beacon market dynamics skills.

Keywords Competence. Competence Management. People Management. Knowledge, Skills and Attitude. Essential Skills 


\section{INTRODUÇÃO}

Presente constantemente em pautas de discussões acadêmicas e empresariais o termo competência pode ser compreendido através de conceitos em construção que ora são excludentes, ora complementares, dependendo do autor que o conceitua.

Pesquisadores estadunidenses como McClelland (1982), Boyatzis (1982) e Lawler (1973), entre outros, associam ao termo competência com a alta performance do indivíduo, ao passo em que autores franceses como Le Boterf (1995) e Zarifian (1999) o descrevem a partir das relações interpessoais e mutabilidade do ambiente.

A abordagem brasileira, por sua vez, representada por autores como Fleury e Fleury (2001), Hipólito (2000), Dutra (2001) e Reis (2000) expande o entendimento acerca do termo ao incluir nele valores agregados, sendo esses econômicos e sociais, a fim de elucidar a competência e seus elementos constituintes. Dentre as obras analisadas para este estudo, percebeu-se que é ausente, nas três correntes, o contexto de aplicação prática onde as definições teóricas das diferentes correntes possam ser confrontadas.

Em concordância com os fundamentos apresentados e levando em consideração a literatura encontrada, analisada e utilizada para redigir o presente estudo, constituiu-se como questão de pesquisa, como os profissionais reconhecem o conceito de competências na prática e como encaram por meio da sua diversidade e aplicação.

O objetivo foi de comparar as percepções de um grupo de profissionais elaboradas acerca do termo com as correntes teóricas e, observar a demanda por competências no ambiente dinâmico de trabalho deste grupo. Empregou-se a entrevista semiestruturada e análise de conteúdo para apuração das informações. Foram desenvolvidas nove entrevistas, sendo três aplicadas à analistas de mercado e seis à pesquisadores seniores de um centro de pesquisa em agronegócio de uma universidade pública.

O recorte na amostra dos sujeitos justificou-se pela dinâmica do enfrentamento do referido centro de pesquisa à variabilidade do contexto micro e macroambientais a que estão inseridos, sendo que uma atuação profissional pautada em competências se constitui elemento chave para o alcance de metas de suas ações.

$O$ estudo vem ganhando força e proporções diferentes, à medida que foi sendo apresentado e discutido em congresso, como por exemplo o recente XIII CONVIBRA - Administração 2016.

Nesta perspectiva, o artigo foi estruturado em cinco momentos distintos, o primeiro recai na diversificação do termo competência e na contextualização do cenário contemporâneo. O segundo aborda a dificuldade subjetiva do termo. O terceiro momento apresenta as metodologia e instâncias filosóficas utilizadas na pesquisa. A quarta demonstra a análise de conteúdo realizada com auxílio de software. É a quinta e última fazem as considerações finais do estudo, suas limitações e sugestão para novos estudos. 


\section{REFERENCIAL TEÓRICO}

As definições sistematizadas na literatura sobre competência vêm sendo agregados novos significados, alguns mais ligados às características da pessoa, outros a função ou cargo por ela exercido. Segundo Ruas (2008) em contextos organizacionais, o termo pode ser julgado a partir de elementos subjetivos, como os conhecimentos, habilidades e atitudes (CHA) do indivíduo.

De acordo com Fleury e Fleury (2001) as tentativas de chegar a uma definição exata do termo se acumulam em variados estudos que abordaram distintos métodos de pesquisa. Esta busca foi inicialmente promovida por David McClelland, em 1973, nos Estados Unidos, o qual procurou distinguir competência de aptidões.

Para Bittencourt (2001), outro debate análogo naquele país foi mediado em 1982 por Richard Boyatzis, associando a competência à performance do indivíduo. Por outro lado, simultaneamente, na década de 1970, foram iniciadas discussões pela escola francesa que pensou as competências como saberes, caracterizando o conceito para além da substância de qualificação.

No caso brasileiro, este debate emergiu na discussão acadêmica, fundamentado inicialmente pela literatura americana, pensando o tema como "input", algo que o indivíduo traz em si. A introdução de autores franceses, como Guy Le Boterf e Philippe Zarifian, contribuiu para o enriquecimento conceitual e empírico, gerando novas discussões.

Frente à variabilidade conceitual, autores nacionais como Fleury e Fleury (2001), Hipólito (2000), Dutra (2001) e Reis (2000) entre outros, sugerem em seus vários níveis de análise do valor agregado pelo indivíduo como principal núcleo do conceito. O tema passou a associar diferentes instâncias de compreensão: no nível da pessoa (a competência do indivíduo), das organizações (as core competence) e dos países (sistemas educacionais e de formação de competências (FLEURY e FLEURY, 2001).

Mesmo com a evolução dos estudos e análises, outras vertentes, decorrentes da visão de autores europeus, surgiram. Segundo Dutra (2014), o foco da definição passou para o contexto, sendo a competência vista como um output, com efetiva legitimação do valor da entrega realizada pelo indivíduo. Ocorreu assim, o deslocamento do princípio que estava sobre o estoque de conhecimento e habilidades para a forma como a pessoa mobiliza seu repertório em determinado contexto, de modo a agregar valor para o meio o qual ela se insere.

Neste cenário de complementaridade o Quadro 1 apresenta uma síntese das correntes teóricas apontando para o núcleo conceitual de cada uma.

Quadro 1: Núcleo do conceito sobre competência

\begin{tabular}{|c|c|c|}
\hline ORIGEM & AUTOR ANO & NÚCLEO DO CONCEITO \\
\hline \multirow{4}{*}{ EUA } & McClelland (1973) & \multirow{3}{*}{ Autoperformance } \\
\hline & Lawler III (1973) & \\
\hline & Boyatzis (1982) & \\
\hline & $\begin{array}{c}\text { Prahalad e Hamel } \\
(1998)\end{array}$ & Competências Essenciais - Core Competence \\
\hline \multirow{2}{*}{ FRANÇA } & Le Boterf (1995) & Inventário de competência \\
\hline & Zarifian (1999) & Inteligência prática \\
\hline \multirow{3}{*}{ BRASIL } & Fleury e Fleury(2001) & Conhecimento, Habilidade, Atitude \\
\hline & Hipólito $(2000,2006,2012)$ & \multirow{2}{*}{ Agregação de valor } \\
\hline & Dutra $(2001,2012,2014)$ & \\
\hline
\end{tabular}

Fonte: Elaborado pelos autores 
O Quadro 2 apresenta a definição do conceito competências por ordem cronológica de publicação dentre os principais autores mais citados pela literatura afim.

\section{Quadro 2: Conceito de competência por ordem cronológica de publicação dentre os principais} autores.

\begin{tabular}{|c|c|}
\hline AUTOR & PREMISSA DE DEFINIÇÃO E/OU CONCEITUAÇÃO \\
\hline \multirow[b]{2}{*}{ Le Boterf (1995) } & $\begin{array}{l}\text { A competência é o conjunto de aprendizagens sociais e comunicacionais nutridas a montante } \\
\text { pela aprendizagem e formação e pelo sistema de avaliações }\end{array}$ \\
\hline & $\begin{array}{l}\text { Competência é um saber agir responsável e que é reconhecido pelos outros. Implica saber } \\
\text { como mobilizar, integrar e transferir os conhecimentos, recursos e habilidades, num contexto } \\
\text { profissional determinado }\end{array}$ \\
\hline Levy-Leboyer (1997) & $\begin{array}{l}\text { Competências são repertórios de comportamentos que algumas pessoas dominam melhor } \\
\text { que outras, o que as fazem mais eficazes em uma determinada situação }\end{array}$ \\
\hline $\begin{array}{l}\text { Prahalad e Hamel } \\
(1998)\end{array}$ & $\begin{array}{l}\text { As competências essenciais são o aprendizado coletivo na organização, especialmente como } \\
\text { coordenar as diversas habilidades de produção e integrar as múltiplas correntes de tecnologia }\end{array}$ \\
\hline Meddeb (1998) & $\begin{array}{l}\text { Competência profissional ...é uma combinação de conhecimentos, de saber-fazer, de } \\
\text { experiências e comportamentos que se exerce em um contexto preciso }\end{array}$ \\
\hline Durand (1999) & $\begin{array}{l}\text { Competências são conhecimento, habilidades e atitudes }(\mathrm{CHA}) \text { necessárias para se atingir } \\
\text { determinados objetivos }\end{array}$ \\
\hline Zarifian (1999) & $\begin{array}{l}\text { A competência é a inteligência prática para situações que se apoiam sobre os conhecimentos } \\
\text { adquiridos e os transformam com tanto mais força, quanto mais aumenta a complexidade das } \\
\text { situações }\end{array}$ \\
\hline $\begin{array}{l}\text { Real Academia } \\
\text { Espanhola (2000) }\end{array}$ & Competência é ...tanto obrigação como atitude ou habilidade para fazer algo \\
\hline Santos (2001) & $\begin{array}{l}\text { Competência não é apenas conhecimento e habilidades para a realização do trabalho (saber } \\
\text { fazer), mas também atitudes, valores e características pessoais vinculados ao bom } \\
\text { desempenho no trabalho (querer fazer) }\end{array}$ \\
\hline $\begin{array}{l}\text { Fleury e Fleury } \\
\text { (2001) }\end{array}$ & $\begin{array}{l}\text { Um saber agir responsável e reconhecido, que implica mobilizar, integrar, transferir } \\
\text { conhecimentos, recursos e habilidades, que agreguem valor econômico à organização e valor } \\
\text { social ao indivíduo }\end{array}$ \\
\hline Zafirian (2003) & $\begin{array}{l}\text { Competência é a tomada de iniciativa e o assumir de responsabilidade do indivíduo sobre } \\
\text { problemas e eventos que ele enfrenta em situações profissionais }\end{array}$ \\
\hline Ruas (2005) & $\begin{array}{l}\text { [...] uma ação através da qual se mobilizam conhecimentos, habilidades e atitudes pessoais e } \\
\text { profissionais, a fim de cumprir certa tarefa ou responsabilidade, numa determinada situação }\end{array}$ \\
\hline $\begin{array}{l}\text { Flink e Vanalle } \\
(2006)\end{array}$ & $\begin{array}{l}\text { As competências podem ser de três tipos: essenciais, funcionais e individuais. Os autores } \\
\text { utilizam os estudos de McClelland para avaliar as competências que devem ser desenvolvidas }\end{array}$ \\
\hline Dutra (2014) & $\begin{array}{l}\text { Entrega é apresentada por e pode ser entendida como a reconhecida contribuição de um } \\
\text { indivíduo ou de um grupo no cumprimento de certa competência, em que o valor agregado ao } \\
\text { negócio é diretamente proporcional à complexidade da entrega. A noção de competência só } \\
\text { é concretizada com uma ação }\end{array}$ \\
\hline $\begin{array}{l}\text { Língua portuguesa } \\
\text { Dicionário Aulete } \\
(2015)\end{array}$ & $\begin{array}{l}\text { Na língua portuguesa é definido pela qualidade de quem consegue resolver uma situação com } \\
\text { maestria }\end{array}$ \\
\hline $\begin{array}{l}\text { Websters-online- } \\
\text { dictionary (2016) }\end{array}$ & $\begin{array}{l}\text { etência define-se como a qualidade de estar adequado ou } \\
\text { ualmente, bem qualificado }\end{array}$ \\
\hline
\end{tabular}

Fonte: Adaptados de Souza, Sampaio, et al., (2008) com complementações e atualizações realizadas pelos autores

As distintas abordagens conceituais remetem a uma dimensão multifacetada, cada autor associa uma interpretação peculiar, dependendo da interpretação ou adaptação em que é empregada. Para Levy-Leboyer (1997), competência pode representar uma gama de elementos, notadamente aplicados no âmbito profissional, descritos como: (1) autoridade, quando quer dizer sobre o poder que se encontra na alta direção; (2) capacitação, quando significa o "saber fazer" e o "saber conhecer" do indivíduo; (3) competição, quando estabelece as metas a serem alcançadas, gerando rivalidade; (4) qualificação, quando na área de gestão de pessoas os psicólogos do trabalho apontam candidatos aptos, ou não, para o cargo, uma referência a capacidade que a pessoa tem de lidar com os próprios problemas e resolvê-los de uma maneira mais efetiva; (5) incumbência, que é utilizada por agentes sociais ao se definirem as tarefas e funções de responsabilidade de um determinado profissional; (6) suficiência, que se dá na execução de um trabalho, quando se tem a 
especificação mínima para ser competitivo. Brandão (1999) descreve a competência nos diferentes níveis organizacionais e afirma que alguns autores elevam o conceito de competência a equipe de trabalho ou mesmo a organização como um todo.

Já Zarifian (2003) assegura que não se deve desprezar a perspectiva da equipe no processo produtivo. Para esse autor, "em cada grupo de trabalho se manifesta uma competência coletiva" (p.32), que é mais do que a simples soma das competências de seus colaboradores. Da mesma forma, Le Boterf (2003) argumenta que, em se tratando de equipes de trabalho, a competência coletiva se forma a partir da coesão das competências individuais que o grupo de trabalho possui. Prahalad e Hamel (1998) estabelecem o conceito de competência essencial (core competence) e o tratam no nível organizacional referindo-se à competência como um conjunto de fatores - conhecimentos, habilidades, valores dos indivíduos e, tecnologias e sistemas físicos e gerenciais - que gera um diferencial competitivo para a organização.

Em estudo semelhante, Luz (2001) desenvolveu um painel ilustrativo a respeito do conceito e a classificação das competências nos diferentes países conforme apresentado no Quadro 8.

\begin{tabular}{|c|c|c|}
\hline PAís & CONCEITO & CLASSIFICAÇÃO \\
\hline CANADÁ & $\begin{array}{l}\text { A educação se inicia com a identificação do que se espera } \\
\text { que o estudante seja capaz de fazer ao final do programa. } \\
\text { A educação baseada em competências é um enfoque } \\
\text { sistêmico sobre o desenvolvimento e formação }\end{array}$ & $\begin{array}{l}\text { - Qualificações acadêmicas } \\
\text { - Qualificações de desenvolvimento } \\
\text { pessoal } \\
\text { - Qualificações para trabalhar em equipe }\end{array}$ \\
\hline $\begin{array}{l}\text { ESTADOS } \\
\text { UNIDOS }\end{array}$ & $\begin{array}{l}\text { As competências são atributos que o empresário de alto } \\
\text { rendimento de hoje busca nos empregados de amanhã. A } \\
\text { produção de alto rendimento está vinculada às novas } \\
\text { formas de organização do trabalho e se baseia no critério } \\
\text { de que o aumento da qualidade, produtividade e } \\
\text { flexibilidade é obtido pela utilização eficaz da força de } \\
\text { trabalho }\end{array}$ & $\begin{array}{l}\text { - Competências práticas } \\
\text { - Competências fundamentais } \\
\text {-Não existe um modelo nacional unificado } \\
\text { de competências; cada estado é autônomo. }\end{array}$ \\
\hline FRANÇA & $\begin{array}{l}\text { A competência é o conjunto de saberes mobilizados em } \\
\text { situação de trabalho }\end{array}$ & $\begin{array}{l}\text {-Saberes ou conhecimentos específicos } \\
\text { - Saberes colocados em prática, saber- } \\
\text { fazer, aptidões } \\
\text {-Inteligência pessoal e profissional, } \\
\text { capacidades }\end{array}$ \\
\hline $\begin{array}{l}\text { REINO } \\
\text { UNIDO }\end{array}$ & $\begin{array}{l}\text { Competência é o conjunto de habilidades e e } \\
\text { conhecimentos que se aplicam no desempenho de uma } \\
\text { função ocupacional, a partir das demandas requeridas } \\
\text { pelo emprego }\end{array}$ & $\begin{array}{l}\text { - Competências específicas do setor } \\
\text { - Competências genéricas } \\
\text { - Competências ou habilidades essenciais }\end{array}$ \\
\hline BRASIL & $\begin{array}{l}\text { A competência é percebida como estoque de recursos, } \\
\text { que o indivíduo detém }\end{array}$ & $\begin{array}{l}\text { - Conjunto de conhecimentos, habilidades } \\
\text { e atitudes } \\
\text { - Conjunto de capacidades humanas }\end{array}$ \\
\hline
\end{tabular}

Fonte: Adaptado de Luz (2001, p. 51) com complementações e atualizações realizadas pelos autores

A competência individual não é aquela que provém da qualificação (habilidade) ou de cargo (fixa), de um funcionário ou posição ocupada por ele, ela advém da pessoa. É a consonância entre conhecimentos, experiências comportamentos e a suas utilizações em situações profissionais (expertises). A mobilização dos colaboradores em um mesmo âmbito, desempenhando atribuições, assumindo responsabilidade, assim como a pró-atividade (iniciativa) diante das situações profissionais e diversas do seu ambiente de trabalho podem ser resumida em competências individuais (ZARIFIAN, 2003).

Estudos realizados por diversos pesquisadores que militam na área, mostram que o conhecimento da pessoa a respeito dos padrões de competência requeridos em seu trabalho, afeta não apenas a percepção (atitudes) o que demonstra as competências. Estes influenciam o interesse do indivíduo ao aprendizado e o desenvolvimento de novos conhecimento e habilidades. Assim, a competência compõe a faculdade do 
colaborador (indivíduo), encarar condições diversas e solucioná-los, em ambientes organizacionais heterogêneos, perplexo e indeterminado (LUZ, 2001).

\section{ASPECTOS METODOLÓGICOS}

Em um estudo envolvendo a pesquisa é fundamental que seus métodos estejam relacionados a determinadas crenças e/ou pressupostos que conduzem à realidade. É essencial que haja reflexão sobre a visão de mundo e de construção do conhecimento que embasa uma pesquisa (SACCOL, 2009).

Assim, com o intuito de observar a ontologia (como as coisas são) e a epistemologia (como o conhecimento do homem é construído), o presente estudo adotou-se do paradigma de pesquisa denominado por pesquisa qualitativa (CASSANDRE e GODOI, 2013; GODOI, BANDEIRA-DE-MELO e SILVA, 2010; POUPART, DESLAURIERS, et al., 2008). Foi justamente esse paradigma de pesquisa, resultante da base epistemológica e ontológica que deu o start ao design e ao método de pesquisa qualitativa e definiu as técnicas de coletas e análise de dados que foram empregados (ORLIKOWSKI e BAROUDI, 1991; CROTTY, 1998).

A escolha do método para este estudo, justifica-se devido a subjetividade do termo competência e dos diversos conceitos encontrados na literatura, assim quanto em sua prática. A abordagem quantitativa foi inviabilizada, pois não se trata de verificar variáveis ou triangular dados estatístico, mas sim de verificar sua interação sujeito-objeto e seus comportamentos quanto a ontologia do termo perante a conduta dos gestores de pessoas em suas organizações.

Após a definição da técnica de coleta de dados, foram realizadas as entrevistas de caráter qualitativo (GODOI, BANDEIRA-DE-MELO e SILVA, 2010) tendo a aplicação de nove entrevistas realizadas em um centro de pesquisa do agronegócio, ligado a uma universidade pública brasileira. O público alvo (amostragem) foi composto de três analistas de mercado e seis pesquisadores seniores.

Como o intuito de tratar e analisar os dados, aplicou-se a análise de conteúdo (BARDIN, 2011) utilizando-se como suporte para realização dessa análise o software Atlas.ti (MUHR, 1991), ferramenta que permite buscar tanto a fiabilidade quanto a consideração do contexto de origem dos dados, no sentido de que o conteúdo não é o material bruto observado, mas o que emerge dele durante o processo de análise. Após este processo procedeu-se a sua transcrição em texto escrito. O objetivo foi compreender os significados nos textos obtidos, levando em consideração as articulações utilizadas pelos sujeitos em suas respostas e as mensagens explícitas e implícitas que as acompanham (BARDIN, 2011).

Apesar da inclinação qualitativa utilizada para a condução das entrevistas, os instrumentos e constructos utilizados na análise de conteúdo não excluiu a abordagem quantitativa concomitantemente, sendo os processos de codificação (e não seus resultados) fontes para as inferências (KRIPPENDORFF, 1990; BARDIN, 2011). Deste modo, os conceitos obtidos foram categorizados de acordo com as falas e descrições dos respondentes, bem como levantadas as frequências de termos-chave enunciados nas falas. A proposta foi a abordagem por unidades temáticas (KRIPPENDORFF, 1990; BARDIN, 2011), cujas categorias foram criadas a partir das próprias narrativas dos respondentes durante as entrevistas.

O estudo utilizou-se de amostragem reduzida devido ao seu caráter preliminar que, posteriormente, serão encadeadas de novas pesquisas (CRESWELL, 2013). 
Quanto aos instrumentos de coleta de dados utilizados para a esta pesquisa, a aplicação da observação, da etnografia ou da pesquisa documental mostrou-se inviável no presente estudo. $\mathrm{O}$ uso de focus group foi a primeira opção cogitada pelo pesquisador, no entanto não se viabilizou dado a falta de disponibilidade, dos profissionais envolvidos, para disponibilizar uma agenda comum. Desse modo, adotouse o uso da entrevista semiestruturada.

As entrevistas ocorreram no período março-junho de 2014, sequencialmente por etapa, as quais foram gravadas em áudio (arquivos mp3 e wav), concedidas através de termos de consentimento e, posteriormente transcritas por profissional especializado - etapa realizada conforme normas de transcrição de entrevistas gravadas (ABNT e NURC/SP n 338 e 331 D2).

As estratégias e as instâncias filosóficas que nortearam esse estudo, em síntese, estão classificados da seguinte forma: (a) quanto à natureza: pesquisa qualitativa; (b) quanto ao gênero: empírico, teórico e metodológico; (c) quanto ao método: entrevistas de caráter qualitativo; (d) quanto a sua lógica: indutiva; (e) quanto a sua base: interpretativista/qualitativo; (f) quanto a sua ontologia: interação sujeito-objeto; (g) quanto a sua base epistemológica: sustentada do construtivismo.

\section{ANÁLISE DOS DADOS COLETADOS}

As questões levantadas pelas entrevistas foram inicialmente apresentadas descritivamente e, ilustradas através de quadros de frequência das respostas. Optou-se por apresentar conjuntamente as respostas dos dois públicos (analistas de mercado e pesquisadores seniores), permitindo a leitura simultânea das considerações destes dos dois grupos profissionais.

Como estratégia de approach inicial entre pesquisador e sujeito da pesquisa, a primeira questão do roteiro buscou conhecer se a competência é um aspecto importante no campo de trabalho dos respondentes e, a partir desta pergunta procurou-se identificar a representação conceitual que estes associavam a este termo.

Todos os sujeitos afirmaram positivamente acerca da importância da competência para o campo de trabalho. Optou-se pela apresentação dos dados de modo a possibilitar análise simultânea das respostas dos dois grupos de sujeitos participantes da pesquisa. A seguir apresentam-se as questões chaves.

A segunda pergunta da entrevista objetivou atinar sobre os aspectos mais importantes sobre a competência advento do campo empírico. Para isso, foi realizado a seguinte pergunta: "Competência é um aspecto importante no seu campo de trabalho? Por quê?" As respostas foram condensadas através da Tabela 1.

Tabela 1: Aspecto importante no campo de trabalho dos respondentes

\begin{tabular}{lcc}
\hline \multirow{2}{*}{ CONCEITO } & \multicolumn{2}{c}{ FREQUÉNCIA } \\
\cline { 2 - 3 } & ABS. & (\%) \\
\hline Conhecimentos específicos & 4 & $44 \%$ \\
Falta de competência & 4 & $44 \%$ \\
Característica do sujeito & 2 & $22 \%$ \\
\hline
\end{tabular}

Fonte: Elaborada a partir dos dados da pesquisa 
Observa-se que, quatro (22\%) dos respondentes perceberam a importância da competência não por sua existência, mas por sua ausência, que leva a problemas relacionados à entrega de resultados. Outros quatro $(22 \%)$ respondentes apontaram para conhecimentos específicos (técnicos, desenvolvimento de habilidades, capacidade analítica) a atribuição de importância à competência.

Os entrevistados não mencionam competências demandadas por cargos específicos para the justificar a importância, centralizando suas percepções a características individuais, aproximando-se, portanto, da concepção de Zarifian (2001, apud DUTRA; FISHER, RUAS; NAKATA, 2006) de que "...não tem sentido vincular a competência ao cargo e sim à pessoa que terá que compreender as demandas do contexto sobre ela e saber mobilizar seu repertório para atender às mesmas de forma adequada” (p. 03).

Seguindo a linha de respostas, era aguardada certa consonância entre o porquê e a definição requerida a cada um dos entrevistados. Entretanto, nem sempre os conceitos levantados foram reproduzidos nas descrições do que se entende do tema, como apontado a seguir. Muito menos uniformes do que na primeira questão, diferentes significados foram listados em busca de uma explicação do termo.

A terceira questão do estudo objetivou conhecer como aquele grupo de profissionais conceitua o termo competência. Assim, realizou-se o seguinte questionamento: Como você conceitua "competência"? As responsas foram sintetizadas através da Tabela 2.

\begin{tabular}{lcc} 
Tabela 2: Conceito de competência segundo os respondentes \\
\hline \multicolumn{1}{c}{ CONCEITO } & \multicolumn{2}{c}{ FREQUÊNCIA } \\
\cline { 2 - 3 } & ABS. & (\%) \\
\hline Habilidade / aptidão & 7 & $78 \%$ \\
Processamento de informações (conhecimento) & 1 & $11 \%$ \\
Aplicação do conhecimento (atitude) & 1 & $11 \%$ \\
Não há definição concreta & 1 & $11 \%$ \\
\hline
\end{tabular}

Fonte: Elaborada a partir dos dados da pesquisa

É notável que as definições de competência criaram uma categoria predominante que a entende como uma habilidade. Os sete $(78 \%)$ respondentes que assim apontaram fizeram-no pensando nas situações cotidianas experimentadas nas funções organizacionais:

Entrevistado 1: Capacidade de lidarmos com uma situação, um problema, procurando alternativas que possam solucionar esse problema, usando do seu conhecimento prático, muitas vezes não sendo necessário um fundamento teórico, mas sim pela habilidade do dia-a-dia. Algumas soluções requerem um aprofundamento maior. Competência é esse conjunto de fatores para solucionar, habilidade para reunir todo essa conhecimento para solucionar esse problema. Entendo competência de maneira mais prática.

Percebe-se, na fala acima, que a compreensão não só está inclinada à aplicação prática, mas está intimamente conectada às situações específicas da organização pesquisada, o que é explícito ao renegar a teoria (como observado na resposta acima) em favor de conhecimento pontual. 
Tal característica é ratificada abaixo, ao incluir qualidades pessoais na forma de agir em busca da competência:

Entrevistado 2: Competência: a pessoa tem que ser capaz de receber informações, analisar as informações, ter capacidade de interpretá-las de forma correta, além de ser capaz de conversar, de ser comunicativo.

Também é possível concluir que competência é compreendida através da imagem de alguém intitulado como competente. Desse modo, parece ser mais objetivo perceber ou tentar ser competente do que entender o conceito em si:

Entrevistado 7: Uma pessoa competente executa as atividades as quais está sujeita de uma maneira eficiente e eficaz. Cada pessoa tem diferentes habilidades e elas talvez não sejam exatamente relacionadas ao trabalho dela, mas quando a proposta junta as habilidades e o trabalho dela de forma integrada e ela faz isso de uma maneira ágil e otimizada, chegando no objeto final, então é uma pessoa competente.

Indo além, há a ênfase não na pessoa competente, mas no exercício de suas funções institucionais:

Entrevistado 4: Profissional competente à aquele que sabe realizar e realiza da maneira correta; ele tem o conhecimento e sabe aplicar esse conhecimento.

Outro fator que merece destaque é a utilização das palavras conhecimentos, habilidades e atitudes; remetem, portanto, ao arcabouço teórico em torno da concepção do composto CHA. Mesmo na resposta que conclui não haver uma definição concreta, é mencionada a necessidade de iniciativa, apesar de a maioria ter evidenciado as habilidades como fator determinante.

Dutra (2008, p.28), já afirmava que "esse enfoque é pouco instrumental, uma vez que o fato de as pessoas possuírem um conjunto de conhecimentos, habilidades e atitudes não é garantia de que elas irão agregar valor à organização".

A fim de aprofundar as respostas anteriores, especialmente acerca das habilidades, a terceira questão foi destinada a instigar a descrição de tais habilidades aplicadas no contexto local, uma vez que se destinava à especificidade das competências.

Vale notar que houve uma mudança na condução das entrevistas de acordo com as respostas da segunda da questão. Inicialmente, esperava-se que as respostas definissem competência em sentido amplo e não necessariamente aplicada na instituição. A terceira, portanto, faria a ligação entre peculiaridades subjetivas e o campo profissional.

O que é possível notar, entretanto, é que as respostas de definição de competência já a fizeram assumindo a competência a atuação técnica, fazendo com que a entrevista procurasse esmiuçar a composição do entendimento do termo aplicado localmente. 
Com o intuito de obter conhecimento sobre as principais competências necessárias para atuar dentro do área de concentração do presente campo empírico, a quarta questão solicitou informação sobre: Quais as principais competências para atuar em sua área? A Tabela 3 representa a sinopse.

Tabela 3: Principais competências da área dos respondentes

\begin{tabular}{lcc}
\hline \multirow{2}{*}{ CONCEITO } & \multicolumn{2}{c}{ FREQUÊNCIA } \\
\cline { 2 - 3 } & ABS. & (\%) \\
\hline Conhecimentos & 4 & $44 \%$ \\
\hline Ser comunicativo & 7 & $78 \%$ \\
\hline Trabalhar em equipe & 1 & $11 \%$ \\
\hline Visão crítica / criterioso & 1 & $11 \%$ \\
\hline Iniciativa & 1 & $11 \%$ \\
\hline Outros & 1 & $11 \%$ \\
\hline \multicolumn{2}{c}{ Fonte: Elaborada a partir dos dados da pesquisa } \\
\end{tabular}

As respostas acerca das principais competências foram tabuladas de acordo com a frequência de citação, havendo, portanto, inclusão de cada termo utilizado a cada vez que proferido, sendo algumas entrevistas geradoras de duas ou mais inserções de dados formadores de categorias.

De forma isolada, a comunicação demonstrou ser a competência mais importante localmente, presente no maior número de respostas. Tal informação é significativa, à medida que fornece indícios que essa característica é necessária como uma competência, mas havia sido mencionada como definição apenas por um dos respondentes (o entrevistado 2, conforme descrito anteriormente).

O trato social como valor de competência também é percebido pelo número de citações do trabalho em equipe, ratificando a conclusão acima, uma vez que nenhum dos respondentes utilizou essa expressão como parte da definição (ignorando nas respostas, mas não no ideário próprio, as competências organizacionais).

A fala a seguir representa adequadamente a opinião dos demais respondentes:

Entrevistado 5: Visão crítica do que está fazendo, ter percepção dos fatos, curiosidade para estudar os fatos. Outra coisa é a competência de trabalhar em equipe, pois não existe análise individual, ela feita pela equipe. E é preciso que as pessoas saibam que é preciso buscar conhecimento o tempo todo.

É possível inferir, desse contexto, que há lacunas entre o que é compreendido acerca do tema e o que é observado como necessário no cotidiano.Por outro lado, nota-se que conhecimento é a palavra-chave como principal competência, em complementaridade com o conceito predominante de habilidade obtido na questão dois. Ainda assim, esse conhecimento mostra ser difuso, não sendo claro quais as diferenças entre as suas formas e peculiaridades, como técnico, processual, teórico e prático.

Outro ponto que pode ser apontado é o fato de que os entrevistados não se preocuparam em utilizar exemplos próprios para suas respostas, levantando dúvidas sobre como a competência é percebida.

A quinta questão vinha ao encontro dessa reflexão, preocupando-se com a observação pontual de demonstrações de competência. Com o intuito de levantar essa discussão, foi indagado a pergunta: No seu entendimento, a competência profissional se manifesta em função das exigências dos contextos de trabalho 
ou porque ela é inerente à pessoa, independentemente dessa demanda? Nesse sentido, você considera tal manifestação como algo realizado de maneira prazerosa ou é algo penoso e causador de estresse? A composição para essa dialética está representada advento da Tabela 4.

Tabela 4: Manifestação da competência segundo os respondentes

\begin{tabular}{lcc}
\hline \multirow{2}{*}{ CONCEITO } & \multicolumn{2}{c}{ FREQUÊNCIA } \\
\cline { 2 - 3 } & ABS. & (\%) \\
\hline Normalmente inato, mas precisa ser desenvolvida / aprendida & 6 & $67 \%$ \\
Surge por necessidade & 2 & $22 \%$ \\
Surge por influência & 1 & $11 \%$ \\
\hline
\end{tabular}

Fonte: Elaborada a partir dos dados da pesquisa

Há um pensamento preponderante que considera a competência como uma característica pessoal, mesmo quando a questão se destinou, explicitamente, ao seu viés profissional.

As respostas revelaram preocupação em como desenvolver essa característica inata, a fim de aplicála no contexto organizacional local; em algumas delas, como no relato abaixo, há inclusive consideração explícita de impossibilidade de criação de competências, ou, ao menos, de algumas delas:

Entrevistado 5: As duas coisas. Existem competências que estão dentro das pessoas e que as situações forçam a desenvolvê-la; não a criá-las. Tem competência que não será criada nunca dentro de uma pessoa. Quando você está desenvolvendo uma competência naquilo que está adequado dentro do seu perfil, será prazeroso e, portanto, o resultado será melhor.

Em relação à segunda parte da resposta, há consenso entre os respondentes de que quando a competência surge durante a aplicação em atividade de afinidade, esta é realizada de forma prazerosa; caso contrário, torna-se penoso.

Conclui-se que mesmo sendo uma característica da pessoa e carente de desenvolvimento, a competência não se limita à área única de atuação, ou seja, a característica do sujeito pode se sobrepor àquilo que está fazendo, à medida que aprende o ofício e executa de forma competente, contradizendo teorias que focam competências específicas a demandas de cargos.

A partir da restrição da resposta que vincula a competência com características endógenas, a entrevista questionou sobre a possibilidade de aprendizado de competência. Diante dessa arena, foi perguntado ao grupo de profissionais: "É possível aprender a ser competente?"

A fim de não induzir possível correção da resposta anterior, esta questão (sexta) evitou termos que remetessem a conclusões do próprio entrevistado acerca da opinião fornecida anteriormente, justificando, portanto, sua não formulação como "Então não é possível aprender a ser competente?" A Tabela 5 agrupa o conjunto de respostas. 
Tabela 5: Possibilidade sobre aprender a ser competente

\begin{tabular}{lcc}
\hline \multirow{2}{*}{ CONCEITO } & \multicolumn{2}{c}{ FREQUÊNCIA } \\
\cline { 2 - 3 } & ABS. & (\%) \\
\hline Sim & 4 & $44 \%$ \\
Sim, com restrições & 2 & $22 \%$ \\
Aprende-se a aprimorá-la com o tempo & 1 & $11 \%$ \\
Aprende-se a descobrir sua competência & 1 & $11 \%$ \\
Depende do meio & 1 & $11 \%$ \\
\hline
\end{tabular}

Fonte: Elaborada a partir dos dados da pesquisa

A estratégia demonstrou ser acertada, à medida que coletou contradições sobre ter de forma inata e poder aprender a ser competente. Sete respondentes disseram ser possível aprender a ser competente, número que contesta a informação anterior de inclinação inata, apesar de três apontarem uniformemente a restrição de necessidade de um bom exemplo para que o processo ocorra.

Apesar da unanimidade de atribuição de importância à competência, observada na primeira questão, nem mesmo para cada um dos próprios sujeitos a definição e suas possibilidades de aprendizagem é inequívoca, como nota-se na fala do entrevistado 9 que, inclusive pondera acerca das causas:

Entrevistado 9: Sim, se você convive com pessoas com diversas habilidades, é muito provável, se você for aberto a tal, você aprende e cresce também... A educação, no país, limita muito. Há muitas coisas que vêm do começo. Se a pessoa não teve oportunidade...

Não só o conceito demonstra ser difuso, como também as situações que estimulam sua aplicação prática. Diante do exposto, a sétima questão objetivou descobri se aquele grupo de profissionais observa variações de demandas de competências no trabalho e o que o que justifica as variações na demanda de competências.

Das nove respostas obtidas, apenas um sujeito afirmou que, após a entrada no mercado, as demandas permanecem as mesmas. Os outros oito afirmaram haver variações. Os motivos, entretanto, não encontraram concordância, sendo proferidas reflexões diversas, como o dinamismo do mercado, as expectativas de cargos, o crescimento individual e das equipes e necessidades ambientais e de condutas pessoais.

Comini, Konuma e Santos (2008) comentam acerca das mudanças ambientais, como a competitividade, que fazem surgir novas competências e impactam na gestão local. Nas entrevistas, nenhum dos respondentes aponta assuntos relacionados à competição. Ao menos que esteja inserida em características mercadológicas, possíveis concorrentes não foram percebidos como agentes causadores de mudanças de competências. Essa peculiaridade poderia ser atribuída ao fato de que a pesquisa foi realizada em instituição pública. Se isso fosse verdadeiro, o mercado também não teria sido mencionado.

Elementos institucionais de gestão interna também foram desconsiderados, bem como o advento de novas competências a partir das variações de demanda de um mesmo cargo. Há indícios, portanto, que as diferentes necessidades não são capazes de alterar os fluxos de trabalho, mais voltados à manutenção das próprias estruturas do que aos acontecimentos externos capazes de radicais alterações internas. 
Assim sendo, nota-se distanciamento entre as percepções dos pesquisados em relação às observações dos três autores acima, que afirmaram em seus estudos que as organizações estão, de fato, tentando "internalizar o conceito de competência" (p. 15).

Finalmente, pode-se inferir que parte das razões de alterações na demanda remontam as tentativas de novas definições de competência, elaborada durante o percurso das entrevistas; ou seja, sem que houvesse uma questão destinada às discussões organizacionais acerca do termo, é evidente que este não é um tema discutido abertamente na instituição onde a pesquisa foi aplicada.

\section{CONSIDERAÇÕES FINAIS}

As respostas que procuravam definir a competência recaíram sobre o composto $\mathrm{CHA}$, demonstrando concordância entre a concepção do conceito e o que foi teoricamente exposto por alguns autores, apesar de restringir descrevê-lo em apenas três elementos. Quando as questões procuraram compreensão inclinada à parte prática, novas classificações surgiram, evidenciando que o conhecimento, as habilidades e as atitudes são apenas uma parte de um contexto maior que engloba a competência.

As reflexões sobre o cotidiano organizacional demonstram que valores são agregados ao conceito, que revela ser mutável e heterogêneo. Tal característica encontra respaldo em definições teóricas que procuram entender a competência não apenas pela entrega de resultados, principalmente no sentido individual, mas também através das relações internas institucionais e do trabalho em equipe.

Os apontamentos acerca da necessidade de comunicação são um indício que o contato com o tema vai além do cumprimento de tarefas. É notável, observando este ponto, que a competência pode ser percebida também pelas suas limitações e ausência de fatores constituintes. Portanto, no imaginário dos pesquisados, competência é definida mais centrada no indivíduo, como nas teorias francesas, mas é sentida no cotidiano como carente de fatores abordados também pela corrente estadunidense.

Torna-se claro que a união de ambas é a mais próxima solução de uma possível definição, encontrada em autores brasileiros que se preocupam tanto com a ação do sujeito quanto com a transferência de saberes, levando à competência uma propriedade compartilhada. A distinção entre a forma de explicar o termo e as maneiras como ele é aplicado, pelos pesquisados, pode ser entendida como a diferença entre competência e o sujeito competente.

$\mathrm{Na}$ pesquisa, à medida que a descrição se restringe predominantemente ao composto $\mathrm{CHA}$ e ao resultado, o competente é aquele que vai além e preocupa-se também com a equipe e com os processos. Como o termo foi abordado em seis das nove entrevistas, através das ações de um sujeito (ou seja, o competente serviu para explicar a competência), percebe-se que os valores pessoais de conduta são atribuídos como necessários para uma definição.

A pesquisa realizada constatou encontros e desencontros entre as teorias e as percepções acerca da aplicação prática da competência. Explicita-se, assim, que ambas ainda carecem de mais estudos e discussões, uma vez que a abordagem teórica, em busca de uma definição, não leva em conta os desvios subjetivos de interpretação do conceito, tampouco aqueles destinados a entregar resultados recorrem às teorias para embasar suas opiniões.

Como limitação de estudo, percebe-se inicialmente a falta de compreensão dos termos pelos sujeitos da pesquisa em relação a prática com a teoria; a baixa amostragem de dados coletados; e a falta de 
diversificação do universo da pesquisa. Como sugestão para novas pesquisas, recomenda-se replicação em múltiplas áreas que envolve direta e indiretamente o conhecimento proposto, ampliando e diversificando a amostragem dos dados coletados. Revela-se, assim, a mesma necessidade de comunicação e compartilhamento, que acabou por permear o tema nas respostas, entre teoria e prática para uma melhor compreensão e aplicação da competência.

\section{REFERÊNCIAS}

BARDIN, L. Análise de conteúdo. 70. ed. São Paulo: Almedina, 2011.

BITENCOURT, C. C. A gestão de competências gerenciais: a contribuição da aprendizagem organizacional. Tese (Doutorado em Administração) Universidade Federal do Rio Grande do Sul - UFRGS. Porto Alegre. 2001.

BOYATZIS, R. E. The Competent Management: A Model for Effective Performance. Nova York: Wiley \& Sons, 1982. 7386.

CASSANDRE, M. P.; GODOI, C. K. Metodologias intervencionistas da teoria da atividade histórico-cultural: abrindo possibilidades para os estudos organizacionais. RGO - Revista Gestão Organizacional, 6, n. Especial, 2013.

COMINI, G.; C, K.; A, S. Sistema de Gestão de Pessoas por Competências: um olhar crítico para a dimensão do desenvolvimento individual. Gestão \& Regionalidade, v. 24, n. 69, jan-abr 2008.

CROTTY, M. The foundations of social research: meaning and perspective in the research process. London: Sage, 1998.

DURAND, T. L. Alchimie de la competénce. Revue française de gestion, v. 1, n. 160, p. 261-292, sem 1999.

DUTRA, J. S. Competências: conceitos e instrumentos para a gestão de pessoas na empresa moderna. 1. ed. São Paulo: Atlas, v. 11, 2014.

DUTRA, J. S. R. Gestão por Competências. São Paulo: Gente, 2001.

FLEURY, A.; FLEURY, M. T. L. Construindo o Conceito de Competências. RAC (ed. Esp.), 2001. 183-196.

FLINK, R. J. D. S.; VANALLE, R. M. V. O desafio da avaliação de competências. Encontro Nacional de Engenharia de Produção - Anais eletrônicos - ABEPRO, 2006. Disponivel em:

<http://www.abepro.org.br/biblioteca/ENEGEP2006_TR450301_7819.pdf>. Acesso em: 06 fev. 2014.

GODOI, K. C.; BANDEIRA-DE-MELO, R.; SILVA, A. B. Pesquisas Qualitativa em Estudos Organizacionais: Paradigmas, Estratégias e Métodos. 2. ed. São Paulo: Saraiva., 2010.

HANASHIRO, D. M. M.; TEIXEIRA, M. L. M.; ZACCARELLI, L. M. Gestão do fator humando: uma visão baseada em Stakeholders. 2. ed. São Paulo: Saraiva, 2008.

HIPÓLITO, J. A. M. A gestão da administração salarial em ambientes competitivos: análise de uma metodologia para construção de sistemas de remuneração por competências. 173f. Dissertação (Mestrado) - Faculdade de Economia, Administração e Contabilidade, Universidade de São Paulo - FEA/USP. São Paulo. 2000.

KRIPPENDORFF, K. Metodología de análisis de contenido: teoría y práctica. [S.I.]: Editorial Paidós, 1990.

LAWLER, E. E. Quality of working life and social accounts. [S.I.]: In M. Dierkes and R.A, 1973.

LE BOTERF, G. D. La compétence - essai sur um attracteur étrange. In: Les editions d'organisations. Paris: Quatrième Tirage, 1995.

LEVY-LEBOYER, C. Gestión de la competencias. Barcelona: Gestión, 1997.

LUZ, T. R. Telemar-Minas: competências que marcam a diferença. (Tese) 307 f. Doutorado em Administração Universidade Federal de Minas Gerais - CEPEAD. Belo Horizonte. 2001.

MCCLELLAND, D. C. Competency assessment methods: history and state of the art. [S.I.]: Hay McBer Research Press, 1990.

MEDDEB, B. L'organization du III millénaire: quelles competences pour le manager. Organizations \& territories, v. 12, n. $1,1998$.

MUHR, T. Atlas.ti: A prototype for the support of text interpretation. Qualitative Sociology, abr. 1991. 349-71.

ORLIKOWSKI, W.; BAROUDI, J. Studying information technology in organizations: research approaches and assumptions. Information Systems Research, v. 2, n. 1, p. 1-28, March, March 1991. 1-28.

POUPART, J. et al. A pesquisa qualitativa: enfoques epistemológicos e metodológicos. Petrópolis, Rio de Janeiro: Vozes, 2008. 
PRAHALAD, C. K.; HAMEL, G. A competência essencial da corporação. In.: MONTGOMERY, Cynthia A.; PORTER, Michael E. (Org.). Estratégia: a busca da vantagem competitiva. Rio de Janeiro: Campus, 1998.

REAL ACADEMIA ESPAÑOLA. Competences pour le manager, 2001. Disponivel em: <http://buscon.rae.es/drael/>. Acesso em: 06 fev. 2014.

REIS, G. G. Avaliação 360 graus: um instrumento de desenvolvimento gerencial. São Paulo: Atlas, 2000.

RUAS, R. L. Observações acerca do Conceito, Natureza e Aplicação das Competências nas Empresas. Porto Alegre: Mimeo, 2009.

SACCOL, A. Z. Um retorno ao básico: compreendendo os paradigmas de pesquisa e sua aplicação na pesquisa em administração. Rev. Adm. UFSM, Santa Maria, 2009. 250-269.

SANTOS, A. C. Gestion del conocimiento: analisis y proyeccion de los recursos humanos. Cuba: Cujae, 2001.

SOUZA, K. M. L. et al. Competências: diferentes abordagens e interpretações como. XV Seminário Nacional de Bibliotecas Universitárias, Campinas, dezembro 2008.

ZAMPIER, M. A.; TAKAHASHI, A. R. W. Aprendizagem e competências empreendedoras: estudo de casos de micro e pequenas empresas do setor educacional. RGO Revista Gestão Organizacional, v. 6, n. 4, Set. / Dez. 2013.

ZARIFIAN, P. Objectif compétence. Paris: Liaisons, 1999.

ZARIFIAN, P. O modelo da competência: trajetória histórica, desafios atuais e propostas. São Paulo: SENAC/SP, 2003. 